\title{
Olivier Bertrand et Jacques Guilhaumou (éds), Le politique en usage (XIV ${ }^{\mathrm{e}}$-XIX $\mathrm{X}^{\mathrm{e}}$ siècles)
}

\section{Chiara Preite}

\section{(2) OpenEdition \\ Journals}

\section{Édition électronique}

URL : http://journals.openedition.org/studifrancesi/28351

DOI : 10.4000/studifrancesi.28351

ISSN : 2427-5856

\section{Éditeur}

Rosenberg \& Sellier

\section{Édition imprimée}

Date de publication : 31 décembre 2006

Pagination : 656

ISSN : 0039-2944

\section{Référence électronique}

Chiara Preite, "Olivier Bertrand et Jacques Guilhaumou (éds), Le politique en usage (xIV ${ }^{\mathrm{e}}-\mathrm{xI} \mathrm{e}^{\mathrm{e}}$ siècles) 》, Studi Francesi [En ligne], 150 (L | III) | 2006, mis en ligne le 30 novembre 2015, consulté le 08 novembre 2020. URL : http://journals.openedition.org/studifrancesi/28351 ; DOI : https://doi.org/10.4000/ studifrancesi.28351

Ce document a été généré automatiquement le 8 novembre 2020.

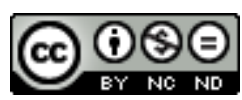

Studi Francesi è distribuita con Licenza Creative Commons Attribuzione - Non commerciale - Non opere derivate 4.0 Internazionale. 


\title{
Olivier Bertrand et Jacques Guilhaumou (éds), Le politique en usage (XIV ${ }^{\mathrm{e}}$-XIX $\mathrm{X}^{\mathrm{e}}$ siècles)
}

\author{
Chiara Preite
}

\section{RÉFÉRENCE}

Olivier BERTRAND et Jacques GUILHAUMOU (éds), Le politique en usage (XIVe-XIX «Langage et Société», nº 113, 2005, pp. 168.

1 Ce numéro de la revue s'intéresse à la langue politique française dans une approche diachronique (XIV ${ }^{e}-\mathrm{XIX}{ }^{e}$ siècles). Les éditeurs (Le politique en usage, pp. 7-9) esquissent les trois étapes constitutives de cette langue: le moyen-âge, où on assiste à la co-présence de deux traditions du politique remontant à Aristote et à Saint-Augustin; la Révolution française, qui renouvelle entièrement la perception du langage politique et la langue politique en soi; la III ${ }^{e}$ République, quand la communication politique devient de masse et que «le politique s'organise en autant de sociolectes que de groupes sociaux» (p. 9). Olivier BERTRAND (Le vocabulaire politique au XIve et xve siècles, pp. 11-32) analyse la période du moyen-âge et le rôle des traducteurs des textes anciens pour retracer la présence d'une double perception du politique constitutive du lexique de l'époque: «la science politique naît aux $\mathrm{XIV}^{\mathrm{e}}-\mathrm{XV}^{\mathrm{e}}$ siècles en France de la philosophie aristotélicienne d'une part et de la théologie chrétienne de l'autre» (p. 29). Marie-Luce DEMONET (Quelques avatars du mot «politique» (XIve-XVIIe siècles), pp. 33-61) s'intéresse à la lexie «politique» se concentrant particulièrement sur son acception d'art qui concerne «la conduite de la cité dans sa réalité pratique» (p. 34). Elle montre l'affranchissement progressif de la politique de la morale religieuse, à la suite de la réception de Machiavel en France, et parallèlement la naissance d'une morale de nature civile. Jacques GUILHAUMou (La langue politique et la Révolution française, pp. 63-91) analyse la «création d'une 'langue nouvelle' de la 'science politique' [qui] est propre de la Révolution 
française» (p. 64). Il retrace une première période (années 1770-1780), qu'il appelle moment proto-politique, où se manifeste la capacité de «thématiser la réalité sociale à l'aide d'objets notionnels inédits» (p. 67). En particulier c'est sur une base sociologique qu'on fonde les «notions-concepts» permettant des «nouvelles expérimentations politiques» (p. 71). C'est lors de la Révolution que ces notions-concepts deviennent réellement opératoires en discours sous forme d'arguments. Maurice TOURNIER ( $L a$ graisse vorace. Petits mythes populaires au service des désignations sociopolitiques à la fin du 19e siècle, pp. 93-123) étudie des mythes populaires au XIX siècle, à savoir «des stéréotypes imagés» (p. 95) qui ont un but polémique. Il retrouve une série d'expressions et de mots-images qui renvoient au mythe de la "graisse vorace», symbolisant la cupidité d'argent du bourgeois $d u x x^{e}$ siècle. Derrière l'utilisation polémique de ce mythe populaire Tournier retrouve également «le grand mythe structural de la lutte des classes» (p. 122).

2 L'hypothèse avancée est que la compétition entre les deux formes syntaxiques dépend du rôle thématique joué par le complément: indifférent exprime une propriété phénoménologique partagée entre le sujet et l'objet. En outre, les principales propriétés syntaxiques et sémantiques de l'adjectif indifférent décrites par l'auteur le distinguent des autres expressions du sentiment. Il s'agit de l'indétermination du sentiment de l'indifférence et la double orientation sentimentale inhérente à indifférent, qui affecte le choix entre le pronom clitique lui, employé pour référer à l'expérienceur, et le pronom disjoint à lui, employé en revanche pour reprendre l'objet du sentiment. 